\title{
The Effects of Foreign and Illegal Labourers Phenomenon on the Availability of Employment Opportunities for the Saudi Youth in the City of Jeddah
}

\author{
Nayef Al-Ghamri ${ }^{1}$ \\ ${ }^{1}$ Department of Human Resources, Faculty of Economics and Administration, King Abdulaziz University, Jeddah, \\ Saudi Arabia \\ Correspondence: Dr. Nayef Al-Ghamri, Department of Human Resources, Faculty of Economics and Administration, \\ King Abdulaziz University, Jeddah, Saudi Arabia. Tel: 966-56-136-4017.
}

Received: March 21, 2016

Accepted: April 6, 2016

Online Published: April 14, 2016

doi:10.5430/ijfr.v7n2p202

URL: http://dx.doi.org/10.5430/ijfr.v7n2p202

\begin{abstract}
The current research study emphasizes the effect of the foreign employees on the availability of work opportunities for the Saudi youth as the current situation is exacerbated by the existence of many young female and male Saudi youths who are available for employment but are currently unemployed.

Today, the Kingdom of Saudi Arabia is now facing the problem of huge number of non Saudi workers who are residing and working illegally. Additionally, there are many problems that are caused by foreign workers such as economic, social and health problems. Some of those illegal laborers who do not abide by the Kingdom's laws and others who earn money from illegal businesses which often leads to money laundering and eventually cause poor performance of the Saudi national economy. The research used a pilot study testing followed by a questionnaire which was sent to 150 managers and customers, yielding one hundred sets of complete data (67\% returns). The data represented the responses of both the managers and workers. The questionnaires were distributed among the employees; bank workers were instructed to collect the required information. In analyzing the data, the researcher used the frequencies, percentages and chi - square statistical analytic tools. The result of the study indicated that workers educational and social backgrounds and lack of training were the most important problem of losing the opportunities of Saudi workers for work. The research findings suggest that there should be a stop to the increasing number of illegal foreign workers so as to help the Saudi youths find work and employment opportunities.
\end{abstract}

Keywords: commercial concealment, foreign labourers, Saudi Arabia, money laundering, pilot study, human trafficking, skilled workers

\section{Introduction}

The subject of foreign and illegal workers in The Kingdom of Saudi Arabia is one of the central issues that strongly impacts the broad range of economic and social security aspects in the Kingdom. The rising importance of addressing this issue is rooted in its fundamental association with providing new avenues for job creation for the Saudi youths of both genders. Thus, the rapid growth rates of foreign as well as illegal workers in the Kingdom is considered a multi-dimensional issue that has various negative consequences represented in the profound fluctuations in the country's economic, social and political structures. These fluctuations are likely to vary from one country to another according to the existing political and economic conditions and the social system that is based in each country. Accordingly, the present study deals with the issue of foreign and illegal workers by addressing several aspects relating to it. The study mainly aims to identify the reasons for the expansion of the numbers of foreign and illegal workers; as well as determining the relative impacts of this phenomenon on the nation's economic performance. Additionally, the study aims to highlight the social impacts of this phenomenon on the community and its members.

\subsection{Research Problem}

The chronic problem of foreign laborers in Saudi Arabia, especially illegal and overstaying workers, is one of the major problems confronting the Kingdom. It is costing the state a loss of its economic resources. If the forgone resources had been invested, the return that could have been created would have led to prosperity and financial 
benefits to the State in general. In addition, the State does not only suffer from economic problems, but also suffers from social, economic and security problems such as theft, embezzlement, health and environmental problems.

\subsection{Significance of the Study}

The significance of this study traces back to the significance of analyzing the economic and social impacts of the vast number of foreign and illegal workers on the national economy's performance and on the society as a whole. The importance of this study is also reflected in the facts which it reveals concerning the necessity to deploy practical strategies to support training and development of the national workforce. The active participation of the domestic workforce is an integral part to achieve the dimensions of sustainable and comprehensive development - in all its fullness.

\subsection{Objectives of the Study}

This study aims to achieve the following objectives:

- Identifying the reasons for the rapid increase of the number of foreign and illegal workers in Saudi Arabia.

- Determining the economic and social impacts of the vast number of foreign workers on the nation's economic performance; as well as its social impacts on the community and its members as a whole.

- Highlighting the serious problems associated with the increasing number of foreign and illegal workers, particularly with regards to the lack of job opportunities for the young Saudi women and men seeking employment opportunities.

- Presenting recommendations that may contribute to limit the growth and expansion of foreign and illegal workers in the future.

\subsection{Research Questions}

- What are the main reasons behind the growing increase in the number of foreign and illegal workers in The Kingdom of Saudi Arabia?

- What are the major economic impacts of foreign and illegal workers on the national economy?

- What are the social consequences associated with the growing number of foreign and illegal workers on the Saudi society and its members?

- What are the additional significant problems associated with foreign and illegal workers that affect the employment of Saudi citizens?

- What remedies are required to be taken into considerations to limit the growth rates of foreign and illegal workers in The Kingdom of Saudi Arabia?

\subsection{The Theoretical Framework of the Study}

As stated at the beginning, this study addresses the issue of foreign and illegal workers in Saudi Arabia. It focuses on the reasons for the increase in number of foreign laborers, the economic and social impacts arising from this issue, and the significant problems associated with the increase of foreign and illegal workers.

\subsection{Reasons for the Rapid Increase of Foreign Labor in Saudi Arabia}

The main reasons for the vast expansion in the numbers of foreign and illegal workers in Saudi Arabia is the State's urgent need to implement numerous economical and developmental projects. On one hand, Saudi Arabia suffers from a shortage of skilled human resources from the nation's citizens and lacks qualified domestic laborers who are able to participate in such huge projects. On the other hand, high wages earned by foreign workers constitute one of the most attractive factors for foreigners and expats to work in Saudi Arabia if compared to the salaries earned in their native countries.

\section{Literature Review}

\subsection{Economic Impacts of Foreign and Illegal Workers}

There are several positive and negative economic impacts of foreign and illegal workers. The study shall review, discuss and compare both positive and negative economic impacts of this aspect: (Assessment of the Kingdom's need for foreign workers, King Saud University, 1425 AH.)

Studies on this aspect demonstrate that foreign and illegal workers ultimately increase the consumption of final goods and services, including free services provided by the government such as education, health, and security. This 
case may be useful for the private sector since the foreign workforce growth has expanded the market, but at the same time, it is draining to the government's budget which generally provides free public services.

The fact of the matter is that illegal workers are crucial to the Saudi economy, as well as vital to certain industries. Foreign laborers significantly contribute to the balance of payments through production of goods and services intended for export, thus increasing the Kingdom's revenues of foreign currency.

Examining the impact of foreign laborers on economic growth, it was found that foreign workers have contributed significantly in increasing the economic growth rates in the Kingdom at a time when Saudi laborers has not been sufficient or properly qualified to finalize the major projects undertaken during the previous decades.

This mass influx of foreign workers has had profound impacts on career opportunities, whereby this variable is considered one of the principal variables set out in this study. The presence of foreign workers - in vast numbers exceeding the nation's actual demands - created significant negative impacts on qualified young Saudi workers. From that estimation, foreign workers compete with domestic workers, thereby leading to the displacement of skilled Saudi youth and undermine the competencies of this important segment of the Saudi society.

However, the most powerful negative impacts of this enormous increase in the number of foreign laborers, is the external remittances sent by foreign workers in the Gulf countries, in general, and Saudi Arabia, in particular, to their home countries. According to the World Bank's Report, Saudi Arabia is the largest Arab country to transfer money and ranked the world's third-largest source of remittances to developing countries reaching up to US\$28.4 billion, annually. Money transfer for expatriate workers during 2012 is expected to exceed US\$26.67 billion. According to Saudi official statistics, the volume of foreign remittances of expatriate workers in the country reaches US\$26.6 billion annually. The number of foreign workers exceeds eight million, where six million actually work in the private sector. Thereby, $90 \%$ of the private sector workforce in Saudi Arabia is of non-Saudis while Saudis account for 10\% only in this sector.

\subsection{Social Impacts of Foreign Labor}

Many studies, including a recent study by (Khalfan, 2011), have provoked concern regarding the size of the population of expatriate workers. The social dimension of such a situation is highly complex, leading to the emergence of new patterns of life, the occurrence of dramatic changes in the ways of living, and various types of social behavior contradictory to each other. Therefore, serious risks and dangers are created that threaten the security and the very existence of the nation. The situation has created a severe imbalance in the population structure, a case that has jeopardized the identity of the region and exposed it to radical changes in terms of the language, values and culture of the local communities. Moreover, it has raised a sense of alienation resulting from multiple dialects used as a means of communication.

Another study by (Al-Mashhadani, 2013) noted that many social and other diverse problems are associated with expatriates working in Gulf societies. Many of them differ in religion, customs, traditions and cultures. Vast differences contribute to increasing crime rates among the expatriate community including theft, forgery and other crimes. The study also revealed the impact of foreigners on the Arab identity, as well as foreigners' impact on children - especially in cases where Asian nannies take care of them. In addition, explorations of the social impact of foreign workers have showed that they are capable of obstructing human resources development programs.

The increase in numbers of expatriate workers, accepting low-wage jobs in the Arab countries of the Gulf Cooperation Council (GCC), hinders the employment of citizens which deprives them of opportunities to develop their abilities and skills.

\subsection{Previous Studies}

In afield study in the city of Riyadh entitled, "Non-Saudi Employment and its Social impacts on the Kingdom of Saudi Arabia" (Asiri, 1403 AH.), the aim of which was to analyze the reasons for the presence of non-Saudi labor and to identify the negative impacts of foreign labor. The study showed that the lack of constraints on the recruitment process was the reason behind the enormous increase in the absolute number of foreign workers in the market. Moreover, a dominating factor that has attracted expatriates to the Kingdom was earning comparatively higher wages than other countries. In addition, foreign workers enjoy a lot of benefits and remuneration schemes such as free medical treatment, free education, housing and transportation - since work systems necessitate the provision of these services to workers. It was clear from this study that foreign employment increasing rates are rising to enormous rates if compared to that of the domestic laborers increasing rates. Foreign workers are scattered throughout the Kingdom in various professions. Finally, the study revealed the lack of equilibrium between citizens who have acquired craft laborer licenses and the total number of laborers in those occupations. 
In a study carried out by the Research Department at the Chamber of Commerce in Riyadh (1400 A.H) entitled, "The reasons for the reluctance of young Saudis to work in the Private Sector", it aimed to identify the reasons for the reluctance of young educated, qualified and trained Saudis to work in the private sector at a time when unemployment tends to spread relatively across the Kingdom. The results of the study supported the view that the percentage of foreigners in the private sector has been growing against a decline in the percentage of citizens engaged in this sector. In addition, a gap exists between the workplace demands of the private sector and the quality and number of Saudi citizen graduates holding technical degrees needed to fill the jobs the private sector is creating. The percentage rate of citizens working in the private sector does not exceed $2.2 \%$, while non-citizens account for $4.10 \%$ of the total workers in this sector.

The study also revealed that proper experience and educational qualifications represent a substantial aspect of the national shortage of manpower in the private sector.

An MA dissertation study by Al-Faisal (1981) entitled "Human Resources Development: The Case Of Vocational Training in Saudi Arabia" aimed to examine the problems and issues related to the shortages in providing skilled and semi-skilled domestic employment to the Saudi market. The study revealed that Saudis themselves may be unwilling to take up certain jobs, considering them to lack social value. Therefore, the negative social perspective is one of the causes that often hinders the involvement of Saudi citizens in vocational education and impedes their pursuit of technical training. The enrollment in vocational training programs has never reached its optimum level. Therefore, vocational education and technical training systems have fallen short in serving the diverse workforce needed by the community, whether for skilled or semi-skilled domestic laborers.

The researcher reached some important results to be briefed as follows: Despite the current advancements in training programs, the human resources development efforts are still insufficient to serve the diverse workforce needs of the country. The main problem of the study was represented in low levels of enrollment in vocational training programs in the Kingdom. The study adopts the view that the reason for such a problem traces back to the separation of primary education from skills training. In addition, shortage of well-trained manpower is due to insufficient numbers of vocational education and training centers. The existing centers are unable to meet current and future human resources requirements in a fast moving economy.

In another study by (Mishkhes, 1987) entitles: "Industrial Employment In Saudi Arabia: Jeddah A Case Study", deals with the conditions of foreign laborers in the province of Jeddah. The researcher addressed the subject of private sector industries in Jeddah. The researcher reached a set of results including: Labor productivity depends on several factors such as skills, the level of training, previous work experience, and other issues such as behavioral trends of workers and their positive work values. The study also showed that the most preferred nationalities of workers in the industrial sector are those from Asian countries or origins due to their high levels of productivity and low wages compared to other categories of workers.

On the other hand, many studies have addressed the issue of foreign workers in Saudi Arabia with regards to social security. A study by Althakafi, (1421 AH.) indicated that the presence of a large number of foreign workers, incorporating differences in customs, traditions, intellectual and religious values, altogether lead to dynamic extents of behavioral variations, a case which further gives rise to an imbalance in the social security order and causes change in the behavior of young people. Another study by Alfaifi, (2012) showed that there are pros and cons for foreign laborers. The most important disadvantage is generating strange customs and traditions in the Saudi society.

In a study by Alfakhry, (2004) entitled, "The Demographics of The Cooperation Council for the Arab States of the Gulf (GCC)", revealed that the imbalance in the population structure affects the national identity as well as the social and cultural national values. This has led to a situation where nationals, in some low population density Gulf countries, have become minorities in their own countries. Besides, many other negative aspects occur - in the forefront of these - is the increasing unemployment rate among the local population at different levels. Therefore, a population study of the GCC countries is becoming exceedingly important and necessary. The balance of the demographic structure is one of the problems confronting the GCC countries in general. It poses more questions about the kind of demographic changes caused by the expanding presence of Asian laborers in these countries.

In view of the above previous studies, the present study deals with the issue of foreign and illegal workers by addressing several aspects. The study mainly aims to identify the reasons for the expansion of the number of foreign and illegal workers; as well as determine the relative impact of this phenomenon on the nation's economic performance; in addition to highlight the social impact of this phenomenon on the community and its members. 


\section{Data Analysis and Interpretation}

\subsection{Research Methodology}

The research method applied to the field of this study is the Descriptive-Analytic Approach. This type of approach is considered one of the most commonly used scientific research approaches in the field of humanities. A Descriptive-Analytic Approach attempts to describe the phenomenon, diagnose its causes, examine the interrelationships among variables and to draw explanatory inferences. As Mulhem (2000) states: "The descriptive analytical approach is considered one form of the rigorous scientific analysis and interpretation leading to the description of a phenomenon or a specific issue by illustrating it quantitatively via the collection of data and summarized information related to the phenomenon with the aim of categorizing and analyzing it as well as subjecting it to thorough investigation" (p.324). Furthermore, the descriptive analytical approach can be defined as: "a series of research procedures that are integrated to describe the phenomenon or the researched topic based on the figures and the data that are collected, classified, processed and thoroughly and adequately analyzed to extract their indications and reach the conclusions and generalizations about the phenomenon or the subject matter under study" (Al-Rashidi, 2000; p.59) The justification for using the descriptive approach is asserted by (Al-Azzawi, 2008) since it is the most commonly used approaches in scientific research. The descriptive approach includes researches that attempt to capture or document current conditions or attitudes, that is, to describe what is existing at the current time. Descriptive research is used to describe, determine or identify the characteristics of a phenomenon being studied. It is used to obtain information concerning the current status of the phenomena without changing or manipulating the environment. Descriptive studies are also conducted to demonstrate associations or relationships between the phenomenon being studied as compared to other phenomena. Therefore, a descriptive approach analyzes, explains, compares and evaluates for the purpose of reaching meaningful assessments and in order to gain insights into a particular phenomenon.

\subsection{The Population of the Study}

The population of this study from which the respondents were selected included businessmen from the overall business community within Jeddah city; in addition to highly educated and esteemed professors in King Abdulaziz University who have scientific background knowledge on the subject of the study under research. A simple random sample of 100 individuals $(n=100)$ were selected from the population of the study.

\subsection{Validity of the Assessment Method}

Utilizing the IBM Statistics $22 ®$ package, the consistency reliability of the assessment method has been validated by determining the correlation coefficient between individual item scores and the total score of the assessment method. The obtained correlation coefficient varied between the scores and is statistically significant at the 0.01 level and most were moderate to high correlation ranging from 0.66 to 0.75 .

\subsection{Reliability of the Assessment Method}

The reliability of the assessment method was explored by the split-half reliability method through measuring the coefficient of overall score of even items and the overall score of odd items using Pearson's Correlation Coefficient, $r$, corrected by the Spearman-Brown formula to get a better estimate of the reliability of the full test. The obtained value of Pearson's Correlation Coefficient, $r$, between the odd and even questions is 0.93, while Spearman-Brown Coefficient is 0.88 and is statistically significant at the 0.01 level indicating a high correlation amongst the scores.

\subsection{Second: The Overall Reliability of the Assessment Method}

Cronbach's Alpha $(\alpha)$ using the Statistical Package for the IBM SPSS Statistics 22® software was used to measure the overall reliability of the assessment method. The overall reliability score of the assessment method is 0.95 , and the reliability scores for the items ranged between 0.75-0.94.

\subsection{Data Analysis Was Performed According to the Following Scenario}

1. Categorization of the sample according to demographic variables.

2. Respond to the following research questions:

- What are the main reasons for the rapid increase of foreign and illegal workers in The Kingdom of Saudi Arabia?

- What are the major economic impacts of foreign and illegal workers on the national economy?

- What are the social consequences associated with the growing number of foreign and illegal workers on the society and its members? 
- Do foreign workers negatively impact job opportunities for young Saudis of both genders?

- What remedies are required to be taken to limit the sharp increase of the number of foreign and illegal workers in The Kingdom of Saudi Arabia?

- According to the respondents' views, what are the hierarchy of nationality preferences for labor in Saudi Arabia?

- What are the additional significant problems associated with foreign and illegal workers that impact the employment of Saudi citizens?

- Due to different variables (gender, age, previous work experience and qualification) are there statistically significant differences between the respondents with regards to the reasons for the expansion in numbers of foreign workers, the economic and social impacts of this phenomenon and other problems related to foreign and illegal workers?

As stated in the previous scenario, the following section fulfills the analysis and interpretation of the respondents' point of views:

3.6.1 First: Classification of the Sample According to Demographic and Social Variables

The following section classifies the sample according to demographic variables (gender, previous work experience, age, and qualification) as shown in the following table:

Table 1. Classification of the sample according to demographic and social variables

$$
(n=100)
$$

\begin{tabular}{ccc}
\hline 1- Gender & Number of respondents & Percentages \\
\hline Male & 81 & 81.0 \\
\hline Female & 19 & 19.0 \\
\hline 2- Previous work experience & & 67.0 \\
\hline 5 years or Less & 67 & 21.0 \\
\hline $6-10$ years & 21 & 7.0 \\
\hline $11-20$ years & 7 & 5.0 \\
\hline $21-30$ years & 5 & \\
\hline 3- Age & & 70.0 \\
\hline Less than 30 years & 70 & 24.0 \\
\hline 31-40 years & 24 & 3.0 \\
\hline 41-50 years & 3 & 3.0 \\
\hline 51-60 years & 3 & 26.0 \\
\hline 4- Qualifications/University degree & & 50.0 \\
\hline Master's and Post graduate studies & 26 & 24.0 \\
\hline Bachelor's degree & 50 &
\end{tabular}

From the table above, it is clear that the majority of respondents participating in this study are classified as young people, since they constitute $94.0 \%$ of the sample size. It is also clear that $26 \%$ of the total sample size hold a Master's degree qualification or are admitted to Post graduate studies, while $50.0 \%$ of the respondents participating in this study hold a bachelor's degree, while $24.0 \%$ are still in High School. Accordingly, we conclude that $50 \%$ of the sample size participants hold a bachelor's degree. Their participation in this questionnaire shall play a significant role in gaining insights into the impact of foreign and illegal workers on career opportunities for young people.

\subsection{Second: Responses to the Research Questions}

\subsubsection{The First Question}

"What are the main reasons for the rapid increase of foreign and illegal workers in The Kingdom of Saudi Arabia?" 
In order to answer this question, several items were designed to help in the analysis and interpretation of the main reasons for the growing presence of foreign and illegal workers in The Kingdom of Saudi Arabia. From the data analysis, it was evident that the weighted average score of the respondents' answers to the various items in the questionnaire on the reasons for the growing increase of foreign and illegal workers in The Kingdom of Saudi Arabia is 4.22 with a standard deviation of 0.78 . Therefore, we conclude that the majority of the questioned sample strongly agree with the factors that lead to the increase of foreign and illegal workers in The Kingdom of Saudi Arabia. Furthermore, it was clear that the most important factor that caused the phenomenon of the increase of foreign workers is: "Foreign workers have exploited Umrah \& Hajj visas to extend their stay in the Kingdom and work in any field, whatsoever, to collect money" This result is supported by the arithmetic mean of 4.33 and a standard deviation of 0.96 . Furthermore, the analysis showed that the second factor that contributed to the increase in the number of foreign and illegal workers in the Kingdom is "the inability of police officers to seize an illegal female worker in private households if she is accompanying the female head of the family in her errands and movements." This result is supported by the arithmetic mean of 4.31 and a standard deviation of 0.90 . Therefore, we conclude that the inability of police officers to seize an illegal female worker in private households if she is accompanied by the female head of the family in her errands and movements is due to the perception of privacy of the Saudi family and the dominance of traditions which are held in high esteem. The analysis also showed that the third factor that contributed to the increase in numbers of foreign and illegal workers in the Kingdom is "the employment of illegal workers by citizens in their households". This result is supported by the arithmetic mean of 4.28 and a standard deviation of 1.03. Therefore, we can conclude that there is a large sector of citizens who employ foreign and illegal workers in their households. This may be due to the low financial costs of employing those foreign workers. Additionally, the analysis also showed that the least factor that contributed to the increase in numbers of foreign and illegal workers in the Kingdom is "the marriage to non-Saudi females, which has resulted in the work of the spouse's relatives - either legally or illegally". This result is supported by the arithmetic mean of 3.84 and a standard deviation of 1.10. Therefore, we can finally conclude from the above analysis and interpretation that the main factors that contributed to the increase in numbers of foreign and illegal workers in the Kingdom are represented in the following:

- Foreign workers have exploited the Umrah \& Hajj visas to extend their stay in the Kingdom and work in any field, whatsoever, to collect money.

- The inability of police officers to seize an illegal female worker in private households if she is accompanying the female head of the family in her errands and movements.

- The employment of illegal workers by citizens in their households.

- The ease of transfer of workers between the cities of the Kingdom, thereby escaping from their sponsor.

- Low wages at the foreign workers' countries of origin is a reason for their recruitment.

\subsubsection{The Second Research Question}

"What are the major economic impacts of foreign and illegal workers on the national economy?"

The data analysis also indicated that the respondents' views about the major economic impacts of foreign and illegal workers on the national economy. It is clear from the results of the data analysis that the weighted average score of the respondent's answers is 4.04 with a standard deviation of 0.65 . Therefore, we conclude that the majority of the questioned sample participants agree that foreign and illegal workers have economic impacts on the national economy. The Indicators' analysis pointed out that the most important economic factor that caused the phenomenon of the increase of foreign workers is: "The strong economic position of Saudi Arabia and higher wages have attracted great numbers of foreign workers" This result is supported by the arithmetic mean of 4.30 and a standard deviation of 0.81 . It also showed that the second factor representing an economic impact of foreign and illegal workers on the national economy is "Areas with a high population density of foreign workers may have a low standard of living and promote infectious diseases transmission." This result is supported by the arithmetic mean of 4.30 and a standard deviation of 0.82 . Therefore, we conclude that the majority of the questioned sample strongly agree that areas with a high population density of foreign workers may have a low standard of living and promotes infectious diseases transmission; a case that poses a serious threat to the demographic structure. The analysis further indicated that the third factor representing an economic impact of foreign and illegal workers on the national economy is "The presence of large foreign commercial groups increase the competition with Saudi businessmen (in trades such as ready-made garments and construction and building materials." This result is supported by the arithmetic mean of 4.18 and a standard deviation of 0.89 . Therefore, we conclude that the majority of the questioned 
sample agree that the presence of large foreign commercial groups is one of the factors that lead to unfair competition - a situation in which Saudi businessmen compete on unequal terms. Additionally, the analysis showed that one of the problems associated with foreign and illegal workers is "electronic fraud crimes and online transfer of funds". This result is supported by the arithmetic mean of 3.79 and a standard deviation of 0.91 . Therefore, we conclude that electronic fraud crimes and online transfer of funds significantly affect the national economy. Based on the above results, we draw the conclusion that the major economic impacts of foreign and illegal workers on the national economy are represented in the following:

- The strong economic position of Saudi Arabia and higher wages have attracted great numbers of foreign workers.

- Areas with a high population density of foreign workers may have a low standard of living and promote infectious disease transmission.

- The presence of large foreign commercial groups increases the competition with Saudi businessmen especially in trades such as ready-made garments and construction as well as building materials.

\subsubsection{The Third Question}

What are the social consequences associated with the growing number of foreign and illegal workers on the society and its members?

Following the data analysis that the weighted average score of the respondents' answers to the questions on the social consequences associated with the growing number of foreign and illegal workers is 4.08 and a standard deviation of 0.73 . Therefore, we conclude that the majority of the questioned sample participants agree that the increase of foreign and illegal workers has social impacts on the Saudi citizen. The analysis also indicated that the most important social consequences associated with the growing number of foreign and illegal workers is as follows: "human trafficking which involves the smuggling or movement of people to Saudi Arabia, as the case in the Southern part of the Kingdom." This result is supported by the arithmetic mean of 4.32 and a standard deviation of 0.85 . Therefore, we can draw the conclusion that human trafficking which involves the smuggling or movement of people to Saudi Arabia, especially through the Southern borders, is one of the most significant social consequences associated with the growing number of foreign and illegal workers in the Saudi Society. These illegal workers are often smuggled across the borders, in violation of the State laws, and are transported to the main cities in Saudi Arabia including Mecca and Jeddah. This situation represents a great threat and a challenge since those illegal and smuggled workers practice all kinds of illegal businesses, thus leading to the occurrence of various negative social phenomena. Additionally, the analysis indicated that "due to the massive increase in the number of foreign workers, some unacceptable traditions have emerged". This case is considered one of the social consequences associated with the growing number of foreign and illegal workers. This result is supported by the arithmetic mean of 4.22 and a standard deviation of 0.88 . Therefore, we conclude from the above that the majority of the questioned participants strongly agree that the emergence of unacceptable social traditions is one of the social consequences that affect the members of the community. Furthermore, it is clear from the analysis that "one of the problems associated with foreign and illegal workers is the popular hatred of foreign workers towards their domestic sponsors (under the kafala system) and citizens in general, as well as the bad treatment of workers to the Saudi family members". This result is supported by the arithmetic mean of 4.12 and a standard deviation of 0.97 . Therefore, we conclude that the majority of the questioned sample agree that the hatred and bad treatment conveyed towards the Saudi family members by foreign workers is one of the negative aspects associated with foreign labor. Toddlers who are assaulted by their caretakers show undebatable proof for the hatred and bad treatment conveyed towards the Saudi family members by foreign workers. The analysis also indicated that "The presence of an enormous number of foreign workers has caused an imbalance in the population structure and a violation of the conventional standards of society". This result is supported by the arithmetic mean of 4.12 and a standard deviation of 1.04. Therefore, we conclude that one of the negative social impacts of foreign workers is the occurrence of an imbalance in the population structure. Due to massive numbers of foreign labor in the community, many local individuals have indulged in strange and unacceptable foreign customs. In addition, a high rate of behavioral deviations has occurred since people do not follow the social and moral rules or values of their society. Accordingly, we conclude from the above that the major social consequences associated with the growing number of foreign and illegal workers are as follows:

- High rates of human trafficking which involves the smuggling or movement of people to Saudi Arabia, as is the case in the Southern part of the Kingdom. 
- High rates of unacceptable habits due to the massive numbers of foreign and illegal workers.

- The widespread hatred and bad treatment conveyed towards the Saudi family members by foreign workers.

- The occurrence of an imbalance in the population structure posing threat to the citizen's security and his family.

3.7.4 The Fourth Question

Do foreign workers negatively impact job opportunities for young Saudis of both genders?

Table 2. Display of answers to the questionnaire related to the negative impacts of foreign workers on job opportunities for young Saudis of both genders

\begin{tabular}{lcccc}
\hline \multicolumn{1}{c}{ Scale } & Replicate & Percentage & Arithmetic Mean & Standard Deviation \\
\hline Strongly Agree & 32 & 32.0 & & \\
\cline { 1 - 3 } Agree & 45 & 45.0 & \multirow{2}{*}{3.94} & \multirow{2}{*}{1.02} \\
\cline { 1 - 3 } Neutral & 10 & 10.0 & & \\
\cline { 1 - 3 } Disagree & 11 & 2.0 & & \\
\cline { 1 - 3 } Strongly disagree & 2 & $100.0 \%$ & & \\
\hline
\end{tabular}

The results of Table 2 have shown that $32.0 \%$ of the questioned participants strongly agree that the presence of foreign workers leads to a rise of unemployment rate among the young Saudi females and males; while $45.0 \%$ agree to this statement, $10.0 \%$ are neutral to the statement, $11.0 \%$ disagree, and $2.0 \%$ strongly disagree. Based on above indicators, we draw the conclusion that the majority of the sample participants believe that the large presence of foreign labor has contributed in raising unemployment rates among the young Saudis of both genders. Those who advocate this view reached $77.0 \%$. This result is supported by the arithmetic mean of 3.94 and a standard deviation of 1.02 .

\subsubsection{The Fifth Question}

What remedies are required to be taken to limit the growth rates of foreign and illegal workers in The Kingdom of Saudi Arabia?

The data analysis indicated that the weighted average score of the respondents' answers to the questionnaire on the required remedies to be taken to limit the rapid increase in rates of foreign and illegal workers in The Kingdom of Saudi Arabia is 3.90 and a standard deviation of 0.66. Therefore, we conclude that the majority of the questioned sample participants agree that the designed remedies contribute towards reducing the size of illegal laborers and minimize its negative impacts on the social and economic levels. Additionally, the analysis of the data indicated that "the importance to raise awareness of the risks of foreign and illegal workers" is one of the significant measures that contributes towards the reduction of the numbers of foreign and illegal workers since it achieved the highest scores in this questionnaire. This result is supported by the arithmetic mean of 4.17 and a standard deviation of 0.83 . Furthermore, it was evident from the analysis that "Visas must be linked to formal letters issued by embassies. Or a bank guarantee must be issued prior to visa issuance to prohibit the stay of foreigners beyond the specified permitted period." Again, this is considered one of the significant measures that contributes towards the reductions of the numbers of foreign and illegal workers, and further leads to the reduction of negative impacts on the national economy. This result is supported by the arithmetic mean of 4.03 and a standard deviation of 1.09. The analysis also showed that one of the required remedies to be taken to limit the increase in rates of foreign and illegal workers in the Kingdom of Saudi Arabia is "It is preferable to allow only skilled labor to work in KSA, such as doctors, engineers and scientists." This result is supported by the arithmetic mean of 4.00 and a standard deviation of 1.13. Therefore, a large proportion of the sample prefer to allow only skilled laborers to work in KSA, such as doctors, engineers and scientists so that the desired level of economic development will be attained. The analysis also indicated that one of the required remedies to be taken to limit the negative impacts of foreign workers on the national economy is "Develop savings and investment tools for foreign workers to help in reducing the volume of external remittances". This result is supported by the arithmetic mean of 3.98 and a standard deviation of 0.84 .

3.7.6 The Sixth Question

What is the hierarchy of nationality preferences for labor in Saudi Arabia? 
Table 3. Display of answers to the questionnaire related to the hierarchy of nationality preferences for labor in Saudi Arabia

\begin{tabular}{ccccccccc}
\hline & $\begin{array}{c}\text { Strongly } \\
\text { Agree }\end{array}$ & Agree & Neutral & Disagree & $\begin{array}{c}\text { Strongly } \\
\text { disagree }\end{array}$ & $\begin{array}{c}\text { Arithmetic } \\
\text { Mean }\end{array}$ & $\begin{array}{c}\text { Standard } \\
\text { Deviation }\end{array}$ & Order \\
\hline Egyptians & 24.0 & 6.0 & 57.0 & 5.0 & 8.0 & 3.33 & 1.14 & 3 \\
\hline Syrians & 16.0 & 7.0 & 56.0 & 10.0 & 11.0 & 3.07 & 1.12 & 6 \\
\hline Yemenis & 25.0 & 9.0 & 42.0 & 10.0 & 14.0 & 3.21 & 1.31 & 4 \\
\hline Indonesians & 25.0 & 17.0 & 44.0 & 7.0 & 7.0 & 3.46 & 1.15 & 2 \\
\hline Filipinos & 39.0 & 17.0 & 36.0 & 4.0 & 4.0 & 3.83 & 1.12 & 1 \\
\hline Indians & 17.0 & 11.0 & 51.0 & 15.0 & 6.0 & 3.18 & 1.08 & 5 \\
\hline Pakistanis & 14.0 & 9.0 & 53.0 & 16.0 & 8.0 & 3.05 & 1.07 & 7 \\
\hline Bengalis & 7.0 & 2.0 & 61.0 & $0 . .13$ & 17.0 & 2.69 & 1.01 & 8 \\
\hline
\end{tabular}

Based on the results of Table 3 for the hierarchy of nationality preferences for laborers in Saudi Arabia, it is clear that Filipinos ranked top since it is supported by the arithmetic mean of 3.83 and a standard deviation of 1.12 . Indonesians ranked second and this is supported by the arithmetic mean of 3.46 and a standard deviation of 1.15 . It is clear that the least nationality preferences to work in KSA are Pakistanis and Bengalis where the evidence is supported by the arithmetic mean of 3.05 and 2.69 consecutively.

\subsubsection{The Seventh Question}

What are the additional significant problems associated with foreign and illegal workers that affect the employment of Saudi citizens?

It is clear from the data analysis regarding the question on "the additional significant problems associated with foreign and illegal workers in the Kingdom" that the weighted average score of the respondents' answers to the questionnaire is 4.07 and a standard deviation of 0.67 . Therefore, we conclude that the majority of the questioned sample agree that there are additional significant problems associated with foreign and illegal workers in the Kingdom. These problems vary so widely in nature causing major issues such as crime, social, economic, ethical and health problems. It is also clear that "Theft and embezzlement operations." is one of the significant problems and crimes associated with foreign and illegal workers since it was the highest score amongst the rest. This result is supported by the arithmetic mean of 4.33 and a standard deviation of 0.85 . Therefore, we conclude that the majority of the sample participants strongly agree that theft and embezzlement operations and practices are two of the most significant problems associated with foreign and illegal workers. Thus, we may draw some implications that this critical problem may pose numerous threats to the national economy. Furthermore, we can conclude that that "Formation of begging gangs" has ranked second among the problems and crimes associated with foreign and illegal workers. This result is supported by the arithmetic mean of 4.28 and a standard deviation of 0.94 . Therefore, we conclude that the majority of the sample participants strongly agree that the formation of begging gangs is one of the most significant problems associated with foreign and illegal workers in the Kingdom posing serious threats to the national security order. It is a highly occurring phenomenon organized by secret criminal organizations. The analysis also indicated that "The practice of black magic and sorcery" has ranked third among the problems and crimes associated with foreign and illegal workers in the Kingdom. This result is supported by the arithmetic mean of 4.21 and a standard deviation of 0.89 . Therefore, we conclude that the majority of the sample participants strongly agree that the practice of black magic and sorcery is one of the most significant problems since citizens may fall victims of sorcerers who cheat them to take their money without offering any benefits in return for such scams. Additioanlly, the analysis also indicated that "The spread of infectious hepatitis due to dirty and contaminated restaurants" is one of the significant health problems that poses threat to the human health and well-being of individuals and the society in general. This particular issue has ranked the fourth among the various problems associated with foreign and illegal workers. This result is supported by the arithmetic mean of 4.17 and a standard deviation of 0.95 . Therefore, we conclude from the above indicator that the majority of the sample participants agree that the spread of infectious hepatitis is one of the risky health issues. Foreign workers, especially low-wage workers and overstaying, illegal workers are more likely to encounter health problems due to massive transmittal of diseases among them. There are no regular medical check-ups conducted for them since they are irregular workers who do not carry any official papers required for renewal; thus making it a difficult task for the health authorities to arrest and deport them back to their countries. Furthermore, the analysis indicated that "The spread of drugs and manufactory of Alcoholic drinks" has ranked fifth among the problems and crimes associated with foreign and illegal workers in the Kingdom. This 
result is supported by the arithmetic mean of 4.17 and a standard deviation of 0.91 . Thus, we conclude that the majority of the sample participants agree that the spread of drugs and manufactory of Alcoholic drinks is one of the most significant crimes associated with foreign and illegal workers. Criminals who practice these activities mainly seek to make money by any means. It was clear that the most significant problems and crimes associated with foreign and illegal workers in the Kingdom of Saudi Arabia are the following:

- Theft and embezzlement operations

- Formation of begging gangs

- The practice of black magic and sorcery

- The spread of infectious hepatitis due to unhygienic and contaminated restaurants

- The spread of drugs and manufactory of Alcoholic drinks

- Trade in illegal visas, forged visas.

- The spread of forged medical certificates.

\section{Conclusions}

In light of the data analysis, the findings of this present study can be summarized as follows:

1. The study revealed that the main factors that contributed to the increase in numbers of foreign and illegal workers in the Kingdom are represented in the following: Foreign workers have exploited Umrah \& Hajj visas to extend their stay illegally in the Kingdom and work in any field, whatsoever, to earn money; The inability of police officers to seize an illegal female worker in private households if she is accompanying the female head of the family in her errands and movements; The employment of illegal workers by citizens in their households; The ease of transfer of workers between the cities of The Kingdom, thereby escaping from their sponsors; And finally, low wages at the foreign workers' countries of origin is a reason for their recruitment.

2. The study also revealed that the major economic impacts of foreign and illegal workers on the national economy are represented in the following: The strong economic position of Saudi Arabia and higher wages have attracted great numbers of foreign workers; Areas with a high population density of foreign workers may have a low standard of living and promote infectious disease transmission; Finally, the presence of large foreign commercial groups increases the competition with Saudi businessmen.

3. The study further revealed that the most powerful negative impact behind the large increase in the number of foreign labor is the external remittances sent by foreign workers in Saudi Arabia to their home countries. External remittances are considered an unfavorable waste of the national wealth. If the foreign resources had been invested, the return that could have been created would have led to the growth of the local economic activities. Saudi Arabia is ranked at top of GCC countries in the volume of foreign remittances of expatriate workers.

4. The also study showed that the major social consequences associated with the growing number of foreign and illegal workers are as follows: High rates of human trafficking which involves the smuggling or movement of people to Saudi Arabia, as is the case in the Southern part of the Kingdom; High rates of unacceptable habits due to the massive numbers of foreign and illegal workers; The common hatred and bad treatment conveyed towards the Saudi family members by foreign workers. And finally, the occurrence of an imbalance in the population structure posing threat to the citizens' security and their families.

5. The study has drawn the conclusion that the large presence of foreign labor has contributed to the rising unemployment figures among the young females and males Saudi citizens. The unemployment rate in the KSA reached almost $6.1 \%$ in 2006, compared to $6.3 \%$ in Bahrain, $1.5 \%$ in Kuwait, $2.3 \%$ in both UAE and Qatar, while topping them all was Oman, which had an employment rate of $14.0 \%$

6. The study showed that the most significant remedies to be taken to reduce the impact of foreign and illegal workers on the national economy, the local community and its members are as follows: The importance to raise awareness of the risks of foreign and illegal workers; Visas must be linked to the issuance of formal employment letters issued by embassies. Or a bank guarantee must be issued prior to visa issuance to prohibit the stay of foreigners beyond the specified permitted period; It is preferable to allow only skilled labor to work in KSA, such as doctors, engineers and scientists. Finally, develop savings and investment tools for foreign workers to help in reducing the volume of external remittances. 
7. The study also revealed that the most significant problems and crimes associated with foreign and illegal workers in The Kingdom of Saudi Arabia are the following: Theft and embezzlement practices; Formation of begging gangs; The practice of black magic and sorcery; The spread of infectious hepatitis due to unhygienic and contaminated restaurants; The spread of drugs and manufactory of Alcoholic drinks; Trade in illegal visas, forged visas. And finally, the spread of forged medical certificates.

\section{Recommendations}

In light of the conclusions just drawn by this research study, the researcher recommends the following:

- The need for the formation of official bodies to continually work to ensure that internal and external Umrah companies and institutions assume full responsibility in regulating the departure of pilgrims within the time limit specified in the visa, so as to minimize the negative phenomenon of retarded pilgrims which adversely affects the national economy.

- Great emphasis should be placed upon campaigns that monitor the validity of visas and undergo a continuous surveillance of foreign workers in popular neighborhoods in order to detain violators of residence and work regulations to ultimately reduce the phenomenon.

- The need to raise public awareness about the negative impacts of illegal workers; and activate legal mechanisms that penalize the concealment of illegal workers.

- The importance to focus on the recruitment of skilled laborers which actively contributes towards the economic and social development, such as doctors, engineers and university professors.

- Study the possibility of implementation of newly designed investment tools for foreign workers to exploit their wages for the benefit of the national economy. An extensive range of smart investment tools shall reduce the incentives to shift and/or transfer these funds out of the Kingdom.

- The need to establish and apply strong legal measures to prevent and detect the phenomenon of informal remittances by foreign workers to their countries of origin.

\section{References}

Al-Azzawi, R. (2008). An Introduction to Research Methodology. Amman, Jordan.

Al-Faifi, M. (2012). Jazan's Youth Break the Social Barriers and Master the Sales Profession. East Magazine, February Edition.

Al-Faisal, F. (1981). Human Resources Development: The Case of Vocational Training in Saudi Arabia. Sonoma State University, Master of Arts in Management.

Al-Fakhri, J. (2004). Expats Workforce and Future Challenges. The Demographics in the Gulf States. East Magazine.

Al-Mashhadani, \& Bin Ali Hussein. (2013). Employment in the Gulf Cooperation Council (GCC) (Challenges and Solutions). Journal of the Gulf Economy, 24.

Al-Rashidi, B. (2000). Educational Research Methodology: A Simplified Applied Vision. New Book House, Kuwait.

Al-Thaqafi, A. (2004). A Workshop on the General Management in Higher Education in the City of Riyadh. May Edition.

Arabs et al. (1425H). Assessing the Need for Expatriate Workforce the Kingdom of Saudi Arabia. King Abdul Aziz City for Science and Technology, General Administration of grants programs.

Asiri, A. (1403 A.H). Non-Saudi Workforce and Its Social Impact on the Saudi Society. A Case Study in the City of Riyadh.

Khalfan, D. (2011). The Economist Newspaper. Kingdom of Saudi Arabia.

Mishkhes, M. (1987). Industrial Employment in the City of Jeddah in Saudi Arabia: A Case Study. Lancaster University, UK.

Mulhem, S. (2000). Research Curricula in Education and Psychology. Al-Maisarah Publication, Printing, and Distribution House. Amman, Jordan.

Research Administration office - Riyadh's Chamber of Commerce. (1400 A.H). Factors Influencing the Negative Desire to Join the Private Sector. 